\title{
Effect of fluorine content on glass stability and the crystallisation mechanism for glasses in the $\mathrm{SiO}_{2}-\mathrm{CaO}-\mathrm{K}_{2} \mathrm{O}-\mathrm{F}$ system \\ R. Casasola, J.M. Pérez, M. Romero* \\ Group of Glassy and Ceramic Materials, Instituto de Ciencias de la Construcción Eduardo Torroja, CSIC \\ C/ Serrano Galvache 4. 28033 Madrid. Spain.
}

\begin{abstract}
This paper provides the results of a study that examines the effect of fluorine content on glass stability (GS) and the crystallisation mechanism for a series of glasses in the $\mathrm{SiO}_{2}-\mathrm{CaO}-\mathrm{K}_{2} \mathrm{O}-\mathrm{F}$ system. Four glass compositions, with fluorine contents ranging from 2.51 to $5.63 \mathrm{wt}$. \%, were analysed by differential scanning calorimetry (DSC). The evaluation of GS was based on various parameters derived from characteristic temperatures of non-isothermal DSC curves, namely, the working range $\left(\Delta \mathrm{T}_{\mathrm{TS}}\right)$, reduced glass transition temperature $\left(\mathrm{T}_{\mathrm{gr}}\right)$, Weinberg $\left(\mathrm{K}_{\mathrm{w}}\right)$, Hrubÿ $\left(\mathrm{K}_{\mathrm{H}}\right)$ and Lu-Liu $\left(\mathrm{K}_{\mathrm{LL}}\right)$ parameters. The predominant crystallisation mechanism for each glass was assessed via the Thakur and Thiagarajan method by determining the variation in crystallisation temperature between powder and bulk glass samples $\left(\Delta \mathrm{T}_{\mathrm{p}}\right)$. The evaluation of glass forming ability (GFA) was based on the critical cooling rate $\left(\mathrm{q}_{\mathrm{c}}\right)$, which is determined from the Weinberg, Hrubÿ and Lu-Liu parameters. The results indicate that an increase in fluorine content leads to a change in the crystallisation process of these glasses, from a mechanism of surface crystallisation that is predominant in glasses with lower fluoride content (MIS-E, MIS-6 and MIS-8 with 2.51, 3.39 and 4.27 wt. \% of fluorine, respectively) to a prevailing volume crystallisation in MIS-10 glass (5.63 wt.\% of fluorine). An increase in fluorine content also leads to a decrease in GFA of the corresponding melts, which results in the segregation of $\mathrm{CaF}_{2}$ crystals during cooling. The results demonstrated by DSC analyses are supported by the results obtained from X-ray diffraction (XRD) and field emission scanning electron microscopy (FESEM).
\end{abstract}

Keywords: cuspidine; DSC; Hrubÿ, Weinberg; Lu-Liu; glass-forming ability; crystallisation mechanism

\footnotetext{
* Corresponding author, Tel.: +34 9130204 40; Fax: + 34913020700.

e-mail address: mromero@ietcc.csic.es
} 


\section{Introduction}

Glass-ceramics are materials that are composed by both amorphous and crystalline phases. Properties of glass-ceramics primarily depend on composition, phase assemblage and microstructure. Therefore, control of the glass-ceramic formation becomes fundamental for producing a material with the desirable final properties. Different procedures exist for obtaining a glass-ceramic from parent glass [1]. The most commonly employed procedure is a two-step process that consists of nucleation and crystal growth. Nucleation concerns the nuclei formation in surface and/or bulk glass. Crystal growth involves the continued development of those nuclei. Furthermore, the crystallisation process is hardly affected by the composition and particle size of the parent glass. Although no single method exists that explains glass devitrification during the heating process, several criteria and methods are available to know how devitrification occurs.

Differential thermal analysis and differential scanning calorimetry are techniques commonly employed to obtain the basic parameters required for understanding glass crystallisation behaviour. These parameters (glass transition temperature, melting point, and crystallisation peak temperature) are obtained directly without additional complex mathematical calculations, which increase the reliability of the results. The most typical and commonly used methods, which are described in the subsequent section, are employed in this paper.

Most commercial glass-ceramic products are produced from glass monolithic pieces through highly automated glass-forming processes that involve appropriate heat treatment. Glassceramic materials can also be prepared through powder processing methods, in which a glass frit or a mixture of different frits is sintered and subsequently crystallised. The nuclei that are developed in the nucleation stage of volume crystallisation are homogeneously and randomly distributed throughout the entire volume of glass. When monolithic glass samples are subjected to a crystallisation process, internal nucleation is required. The crystal growth is known as bulk crystallisation. Conversely, when the glass-ceramic material is to be produced from glass powder compacts, crystallisation must begin at the surface of the glass particles. The relict surfaces of the glass grains serve as nucleating sites for the growth of the crystalline phases. In this case, glass softening must occur prior to the completion of the crystallisation process. 
R. Casasola, J.M. Pérez, M. Romero. Effect of fluorine content on glass stability and the crystallisation mechanism for glasses in the $\mathrm{SiO}_{2}-\mathrm{CaO}-\mathrm{K}_{2} \mathrm{O}-\mathrm{F}$ system

Several noteworthy synthetic glass-ceramics have been developed based on fluorine-containing crystalline phases: fluorapatite $\left(\mathrm{Ca}_{5}\left(\mathrm{PO}_{4}\right)_{3} \mathrm{~F}\right)$, potassium fluorphlogopite $\left(\mathrm{K}_{2} \mathrm{Mg}_{6} \mathrm{Si}_{6} \mathrm{Al}_{2} \mathrm{O}_{18} \mathrm{~F}_{4}\right)$, fluorrichterite $\left(\mathrm{KNaMg}_{5} \mathrm{Si}_{8} \mathrm{O}_{22} \mathrm{~F}_{2}\right)$ and fluorcanasite $\left((\mathrm{Na}, \mathrm{K})_{6} \mathrm{Ca}_{5} \mathrm{Si}_{12} \mathrm{O}_{30} \mathrm{~F}_{4}\right)$ are some examples. These phases are the fluorine analogues of the natural hydroxyl-containing mineral phases. The charge-to-size ratio of a fluorine anion is similar to the charge-to-size ratio of a hydroxyl ion, and fluorine is easier to retain in the glass melt [2]. Fluorosilicates are endowed with high fracture toughness and bending strength. Fluorosilicates-containing glass-ceramics are characterised as being less sensitive to superficial damages and exhibit higher thermal shock, erosion and fracture strength than common ceramic materials.

The discovery of a single glass composition that is compatible with both surface and bulk crystallisation processes is challenging. F-miserite is a chain silicate with a complex structure $\left(\mathrm{KCa}_{5}\left(\mathrm{Si}_{2} \mathrm{O}_{7}\right)\left(\mathrm{Si}_{6} \mathrm{O}_{15}\right)(\mathrm{F}, \mathrm{OH})_{2}\right)$. This crystalline phase, which strengthens glass-ceramic materials, has been described as a pyroxenoid (wollastonite) or hydrous pyroxenoid derivative (pectolite). In the late 1990s, Pinckney et al. [3] published a paper that described a new family of glass-ceramics that are based on the complex chain silicate miserite. With little or no change in composition, it was compatible with both bulk and surface crystallisation processes. Their study examined highly crystalline glass-ceramics that contain a microstructure composed primarily of interlocked, lath- or log-shaped miserite crystals with pronounced cleavage planes. This microstructure provided maximum abraded flexural strength values of $235 \mathrm{MPa}$ and $\mathrm{K}_{\mathrm{Ic}}$ values greater than 3.0 $\mathrm{MPa} \cdot \mathrm{m}^{1 / 2}$. These glass-ceramics are useful for various applications in which moderately high strength and toughness are desired. However, despite such promising properties, no additional investigations on miserite glass-ceramics have been published since the paper by Pinckney et al. was presented [3].

Another interesting fluorine-containing crystalline phase in glass-ceramics is cuspidine $\left(\mathrm{Ca}_{4} \mathrm{Si}_{2} \mathrm{O}_{7} \mathrm{~F}_{2}\right)$, a sorosilicate with isolated $\left(\mathrm{Si}_{2} \mathrm{O}_{7}\right)^{6-}$ double tetrahedral groups. Cuspidine is the most abundant high temperature phase in mould fluxes used in continuous casting of steel [4]. Mould flux glasses act as a lubricant between the water-cooled mould and the steel. Their viscosity, heat transfer characteristics and the break temperature, which generally corresponds to the crystallisation of cuspidine, are all critical to the continuous casting process [5]. The crystallisation of the mold flux is regarded as one of its most important properties, as it primarily controls the heat transfer and influences the lubrication of steel in continuous casting [6]. 
R. Casasola, J.M. Pérez, M. Romero. Effect of fluorine content on glass stability and the crystallisation mechanism for glasses in the $\mathrm{SiO}_{2}-\mathrm{CaO}-\mathrm{K}_{2} \mathrm{O}-\mathrm{F}$ system

The main purpose of the present paper is to study the effect of fluorine content on glass stability, glass forming ability and the crystallisation mechanism for a series of glasses that are based on fluor-miserite composition $\left(\mathrm{SiO}_{2}-\mathrm{CaO}-\mathrm{K}_{2} \mathrm{O}-\mathrm{F}\right.$ system). This research is part of a larger study that explores the crystallisation process and final properties of the resulting glass-ceramic materials, in an effort to discover novel applications in the field of glass-ceramic glazes for ceramic tiles.

\section{Experimental}

\subsection{Preparation of glasses}

A glass in the $\mathrm{SiO}_{2}-\mathrm{CaO}-\mathrm{K}_{2} \mathrm{O}-\mathrm{F}$ system with the stoechiometric composition of fluor-miserite, $\mathrm{KCa}_{5} \mathrm{Si}_{8} \mathrm{O}_{22}(\mathrm{~F})_{2}$ and hereafter designated MIS-E glass, was formulated based on a reagent grade $\mathrm{CaCO}_{3}, \mathrm{~K}_{2} \mathrm{CO}_{3}, \mathrm{CaF}_{2}$ and silica sand with low contents of iron oxide. Based on the composition of MIS-E, three additional glass compositions were formulated. They contained fluorine contents of 6,8 and 10\% and were designated MIS-6, MIS-8 and MIS-10, respectively.

The mixtures were homogenised in a planetary ball mill (TURBULA) for $15 \mathrm{~min}$. The batches were then melted in an electric furnace at $1450^{\circ} \mathrm{C}$ for $2 \mathrm{~h}$ in alumina-silica crucibles. Frit glasses were obtained by pouring the low-viscosity melts into cool water. Moreover, monolithic glass samples were prepared by casting the melt into an approximately $10 \times 1 \times 1 \mathrm{~cm}$ brass mould and subsequently annealing for $2 \mathrm{~h}$ at a temperature of $\mathrm{T}_{\mathrm{g}}-100^{\circ} \mathrm{C}$ to avoid crystallisation. $\mathrm{T}_{\mathrm{g}}$ values for each glass composition were determined from the results of differential scanning calorimetry (DSC), which was conducted previously on glass samples with the same composition.

2.2. Physical characterisation

The chemical analysis of the resulting glasses was determined by X-ray fluorescence (XRF) using a BRUCKER S8 Tiger spectrometer. The analysis was performed on pressed pellets of powder glass samples $(<63 \mu \mathrm{m})$. The evaluation of the amorphous nature of the glass after melting was performed by X-ray diffraction (XRD) using BRUKER D8 Advance equipment with Ni-filtered $\mathrm{Cu} \mathrm{K} \alpha$ radiation operating at $30 \mathrm{~mA}$ and $40 \mathrm{kV}$. Data were recorded in the 5$60^{\circ} 2 \theta$ range (step size $0.019732^{\circ}$ and $0.5 \mathrm{~s}$ counting time for each step). 
R. Casasola, J.M. Pérez, M. Romero. Effect of fluorine content on glass stability and the crystallisation mechanism for glasses in the $\mathrm{SiO}_{2}-\mathrm{CaO}-\mathrm{K}_{2} \mathrm{O}-\mathrm{F}$ system

The glass stability (GS) study was conducted by DSC on both powder $(<63 \mu \mathrm{m})$ and bulk or monolithic $(2 \times 2 \times 3 \mathrm{~mm})$ glass samples. DSC runs were performed from room temperature to $1400^{\circ} \mathrm{C}$, at a heating rate of $50^{\circ} \mathrm{C} \cdot \mathrm{min}^{-1}$ under flowing air in a SETARAM Labsys Thermal Analyser. Samples of $40 \mathrm{mg}$ were placed in platinum crucibles and calcined $\mathrm{Al}_{2} \mathrm{O}_{3}$ was used as the reference material. The DSC curves were normalised with respect to the sample weight. The temperature precision given by the equipment is $\pm 0.1{ }^{\circ} \mathrm{C}$. Each measurement was reproduced three times in order to estimate experimental errors.

To confirm the effect of fluorine on the preferential crystallisation mechanism (surface or bulk), monolithic $(5 \times 5 \times 5 \mathrm{~mm})$ glass samples of each glass composition were subjected to thermal treatment to promote crystal growth. Their microstructure was observed by field emission scanning electron microscopy (FESEM) with a HITACHI S-4800P microscope using an acceleration voltage of $20 \mathrm{kV}$. Transversal sections of crystallised glasses were polished to a 1 $\mu \mathrm{m}$ finish using diamond pastes after initially grinding with $\mathrm{SiC}$ powder. The samples were subsequently etched for $10 \mathrm{~s}$ in a solution of $5 \% \mathrm{HF}$, ultrasonically washed with distilled water and ethylic alcohol, dried and coated with Au-Pd in a Balzers SCD 050 sputter.

Generally, when a glass is subjected to heat treatment, crystallisation occurs due to the energy reduction that transpires when the structurally amorphous phase (glass) is transformed in a stable solid phase with a regular ordered geometry [8]. Glass stability denotes the resistance of a glass to crystallisation on heating. The GS of each glass composition, both in bulk and powder conditions, was evaluated from the characteristic temperatures obtained from DSC curves; namely, the glass transition temperature $\left(T_{g}\right)$, onset and peak crystallisation temperatures $\left(T_{x}\right.$ and $T_{p}$, respectively), and melting temperature $\left(T_{m}\right)$, which is the temperature at the minimum of the endothermic peak. Various parameters can be defined from these temperatures to establish the glass stability on heating and the predominant crystallisation mechanism.

The crystallisation of a glass can proceed through two mechanisms: volume or bulk crystallisation and surface crystallisation. In volume crystallisation, the crystals are homogeneously and randomly distributed throughout the entire volume of the glass. Conversely, in surface crystallisation, crystals develop at the glass surface and then grow into the glass volume. To ascertain the predominant crystallisation mechanism for each glass composition, the Thakur and Thiagarajan method [8] was employed to determine the crystallisation temperature difference between powder and bulk glass samples, $\Delta \mathrm{T}_{\mathrm{p}}$, as follows: 
R. Casasola, J.M. Pérez, M. Romero. Effect of fluorine content on glass stability and the crystallisation mechanism for glasses in the $\mathrm{SiO}_{2}-\mathrm{CaO}-\mathrm{K}_{2} \mathrm{O}-\mathrm{F}$ system

$\Delta T_{p}=T_{p(f i n e)}-T_{p(c o a r s e)}$

If glass devitrification occurs through surface crystallisation, a strong dependence on glass particle size would be expected, with $\Delta \mathrm{T}_{\mathrm{p}}$ yielding negative values, as shown in Eq. 1.

Several parameters are used to determine GS; they are based on characteristic temperatures that are determined from the non-isothermal DSC analyses. An evaluation of the thermal stability of each glass was achieved by measuring its working range, which is the temperature interval between $T_{g}$ and the onset of crystallisation, as follows:

$\Delta \mathrm{T}_{\mathrm{TS}}=\mathrm{T}_{\mathrm{x}}-\mathrm{T}_{\mathrm{g}}$

The smaller this temperature interval, the lower is the thermal stability of the glass and the more difficult it is to prevent partial crystallisation during any working operation, including sintering [9].

Other parameters of GS on heating are as follows:

- Reduced glass transition temperature $\mathrm{T}_{\mathrm{gr}}[10]$,

$T_{g r}=\frac{T_{g}}{T_{m}}$

- Weinberg parameter [11],

$K_{w}=\frac{T_{\mathrm{s}}-T_{q}}{T_{\mathrm{m}}}$

- Hrubÿ proposed his own parameter, $\mathrm{K}_{\mathrm{H}}$, to probe glass stability against crystallisation on heating as defined by [12],

$K_{H}=\frac{T_{w}-T_{g}}{T_{m}-T_{w}}$

- Lately, Lu and Liu proposed a new criterion $\mathrm{K}_{\mathrm{LL}}[13,14]$,

$K_{L L}=\frac{T_{\mathrm{w}}}{T_{g}+T_{\mathrm{MI}}}$

More recently, Kozmidis-Petrović [15] performed a theoretical analysis of relative changes in GS parameters for some oxides and chalcogenide glasses. The study indicates that glasses 
R. Casasola, J.M. Pérez, M. Romero. Effect of fluorine content on glass stability and the crystallisation mechanism for glasses in the $\mathrm{SiO}_{2}-\mathrm{CaO}-\mathrm{K}_{2} \mathrm{O}-\mathrm{F}$ system

present GS values that are independent of their chemical composition and, thus, any prediction is unachievable. Therefore, it was important to determine these parameters to assess the effect of fluorine content on GS of the subject glasses.

Glass-forming ability (GFA) is defined as the ease of a melt to form a glass during cooling [13, 14]. It can be evaluated by the critical cooling rate $q_{c}$, which is the lowest rate, from melting to $\mathrm{T}_{\mathrm{g}}$, for preventing crystallisation. This critical cooling rate can be determined from the Weinberg, Hrubÿ and Lu-Liu parameters by the following equations:

$$
\begin{aligned}
& \log _{10} q_{W}=4.44-21.4 \cdot K_{W} \\
& \log _{10} q_{H}=3.17-2.26 \cdot K_{H} \\
& \log _{10} q_{L L}=17.7-34.6 \cdot K_{L L}
\end{aligned}
$$

Note that $T_{p}$ instead of $T_{x}$ has been used to determine the $K_{W}, K_{H}$ and $K_{L L}$ parameters by equations (4), (5) and (6) to evaluate GFA from GS parameters. Nascimento et al. [16, 17] explained that, in general, the use of $T_{p}$ instead of $T_{x}$ leads to better regression results when Eqs. (7), (8) and (9) are utilised.

\section{Results}

Table 1 shows the theoretical and experimental chemical composition determined by X-ray fluorescence of the investigated glasses.

Figure 1 presents the XRD diffractograms of the powder glass samples. The diffractograms corresponding to MIS-E, MIS-6 and MIS-8 glasses exhibit the typical broad amorphous halo, which is characteristic of the disordered structure of glasses. Conversely, the pattern of the glass MIS-10 sample shows diffraction peaks, which indicate the presence of a crystalline phase.

Figure 2 shows the DSC thermograms from fine $(<63 \mu \mathrm{m})$ and coarse samples obtained from the four glasses. The first endothermic jump in the baseline of all curves corresponds to $T_{\mathrm{g}}$. As expected, $\mathrm{T}_{\mathrm{g}}$ is independent of the glass particle size in each glass composition, because this temperature is an intrinsic property of the glass, i.e., it only depends on the composition and the cooling rate from the melting temperature [18]. Above $\mathrm{T}_{\mathrm{g}}$, different exothermic effects indicate 
R. Casasola, J.M. Pérez, M. Romero. Effect of fluorine content on glass stability and the crystallisation mechanism for glasses in the $\mathrm{SiO}_{2}-\mathrm{CaO}-\mathrm{K}_{2} \mathrm{O}-\mathrm{F}$ system

that the base glasses undergo crystallisation processes that are followed by an endothermic fall at approximately $1110^{\circ} \mathrm{C}$, which is indicative of liquid phase formation and melting of the main crystalline phases that formed during heating in $\mathrm{CaF}_{2}$-containing glasses [19]. Table 2 lists the values of the characteristic temperatures, $\mathrm{T}_{\mathrm{g}}$ and $\mathrm{T}_{\mathrm{x}}$, derived from the DSC curves.

Table 1. Theoretical and experimental (XRF) chemical composition (wt\%) of the investigated glasses. The errors in the experimental composition are approximately $\pm 0.2 \mathrm{wt} \%$.

\begin{tabular}{l|cc|cc|cc|cc}
\cline { 2 - 8 } \multicolumn{2}{c|}{} & \multicolumn{2}{c|}{ MIS-E } & \multicolumn{2}{c|}{ MIS-6 } & \multicolumn{2}{c|}{ MIS-8 } & \multicolumn{2}{c}{ MIS-10 } \\
\cline { 2 - 9 } & Theo. & Exp. & Theo. & Exp. & Theo. & Exp. & Theo. & Exp. \\
$\mathrm{SiO}_{2}$ & 56.81 & 54.05 & 55.91 & 52.80 & 54.72 & 52.13 & 53.53 & 50.82 \\
$\mathrm{Al}_{2} \mathrm{O}_{3}$ & - & 4.63 & - & 5.70 & - & 7.66 & - & 7.87 \\
$\mathrm{CaO}$ & 33.14 & 34.02 & 32.62 & 33.36 & 31.92 & 31.37 & 31.23 & 32.21 \\
$\mathrm{~K}_{2} \mathrm{O}$ & 5.56 & 4.79 & 5.48 & 4.76 & 5.36 & 4.56 & 5.24 & 4.48 \\
$\mathrm{~F}_{2}$ & 4.49 & 2.51 & 6.00 & 3.39 & 8.00 & 4.27 & 10.00 & 5.63 \\
\hline
\end{tabular}

Table 2. Characteristic temperatures $\left(\mathrm{T}_{\mathrm{g}}, \mathrm{T}_{\mathrm{x}}\right)$ and $\Delta \mathrm{T}_{\mathrm{p}}$ values derived from the DSC curves for each sample and size. The errors in the characteristic temperatures are approximately $\pm 2-3^{\circ} \mathrm{C}$.

\begin{tabular}{c|cccccccc} 
& \multicolumn{2}{c}{ MIS-E } & \multicolumn{2}{c}{ MIS-6 } & \multicolumn{2}{c}{ MIS-8 } & \multicolumn{2}{c}{ MIS-10 } \\
\cline { 2 - 8 } & Monolithic & Powder & Monolithic & Powder & Monolithic & Powder & Monolithic & Powder \\
\hline $\mathrm{T}_{\mathrm{g}}\left({ }^{\circ} \mathrm{C}\right)$ & 679 & 677 & 651 & 648 & 631 & 631 & 598 & 600 \\
$\mathrm{~T}_{\mathrm{x}}\left({ }^{\circ} \mathrm{C}\right)$ & 865 & 784 & 863 & 738 & 767 & 729 & 681 & 741 \\
\hline
\end{tabular}




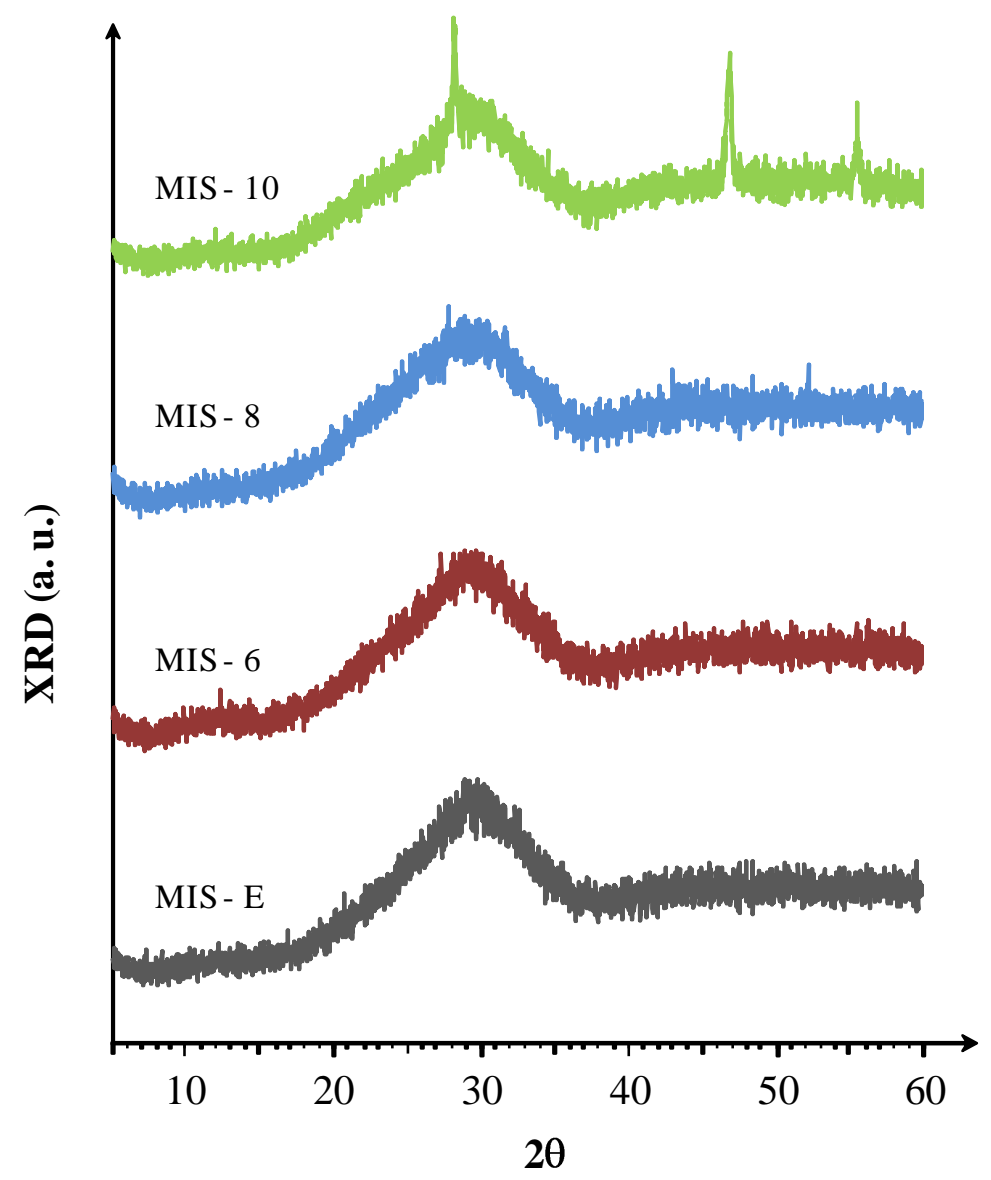

Figure 1. XRD of the powder glass samples $(<63 \mu \mathrm{m})$

For a better depiction of the effect of F- ions on the overall crystallisation process, Fig. 3

illustrates the evolution of $\Delta \mathrm{T}_{\mathrm{p}}$ with fluorine content. $\Delta \mathrm{T}_{\mathrm{p}}$ values were calculated from the values of $T_{p}$ in powder and bulk samples for each glass composition. The effect of fluorine on the crystallisation mechanism of these glasses can be also evaluated from the values of the Tgr and $\Delta \mathrm{T}_{\mathrm{TS}}$ parameters. Figure 4 displays the values of $\mathrm{T}_{\mathrm{gr}}$ for the different glass compositions in both monolithic and powder state. $\mathrm{T}_{\mathrm{gr}}$ is related to the critical cooling rate [20], thus, the higher the value of Tgr, the lower is the required qc to prevent crystallisation from the melt during cooling. The lines depicted in Fig. 4 establish the $\mathrm{T}_{\mathrm{gr}}$ interval, which signifies the gap between surface and bulk crystallisation. James [21] and Zanotto [22, 23] demonstrate that glasses that display only surface crystallisation have a Tgr higher than approximately $0.58-0.60$, whereas glasses with $\mathrm{T}_{\mathrm{gr}}<0.58-0.60$ exhibit volume crystallisation. Fig. 5 depicts the evolution of $\Delta \mathrm{T}_{\mathrm{TS}}$ with fluorine content for both powder and bulk glass samples. The lower the value of $\Delta \mathrm{T}_{\mathrm{TS}}$, the 
R. Casasola, J.M. Pérez, M. Romero. Effect of fluorine content on glass stability and the crystallisation mechanism for glasses in the $\mathrm{SiO}_{2}-\mathrm{CaO}-\mathrm{K}_{2} \mathrm{O}-\mathrm{F}$ system

lower is the thermal stability of the glass and the easier it is to develop crystalline phases during heating [24].
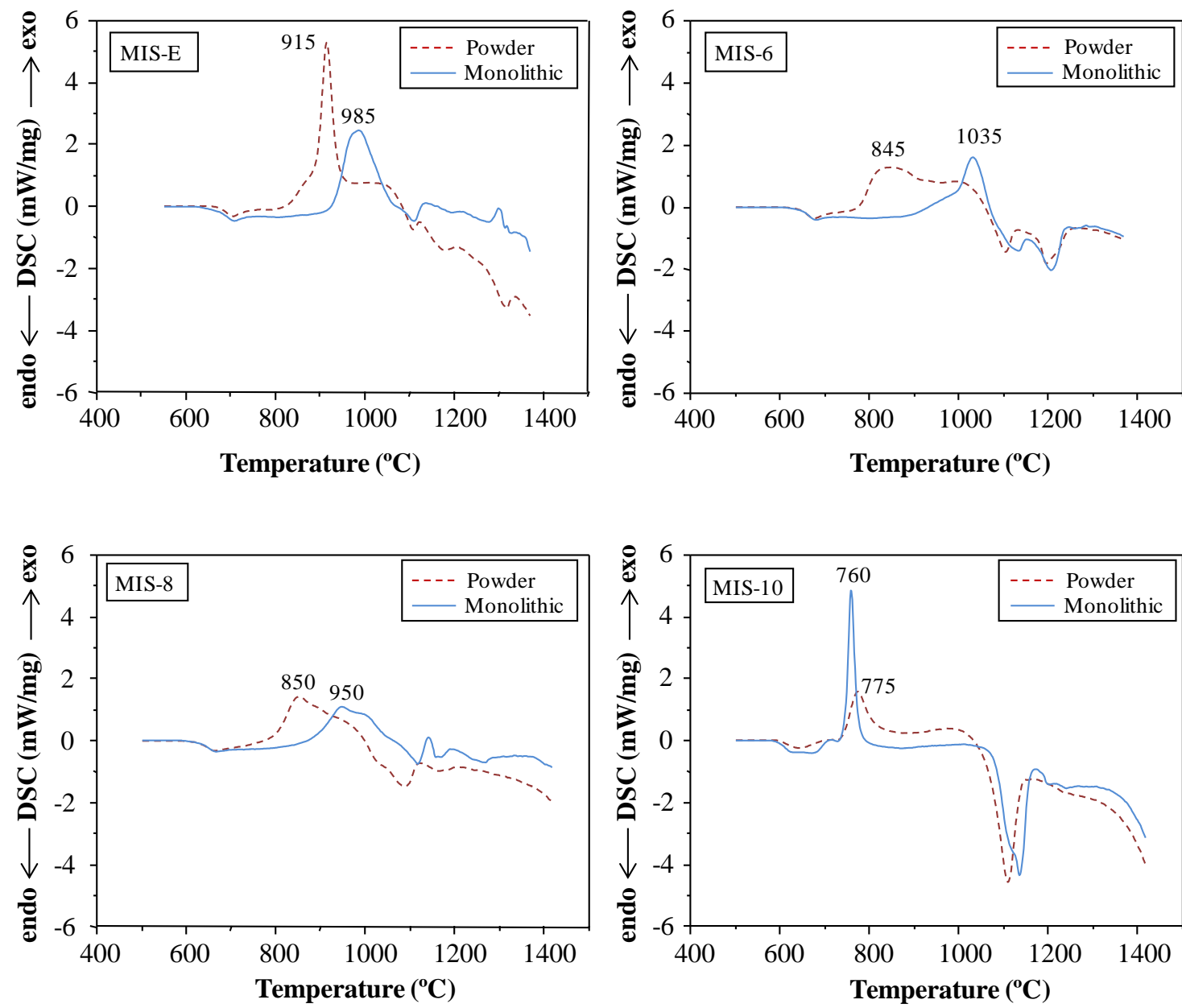

Figure 2. DSC thermograms from fine $(<63 \mu \mathrm{m})$ and coarse glass samples at a heating rate of $50^{\circ} \mathrm{C} \cdot \mathrm{min}^{-1}$. 


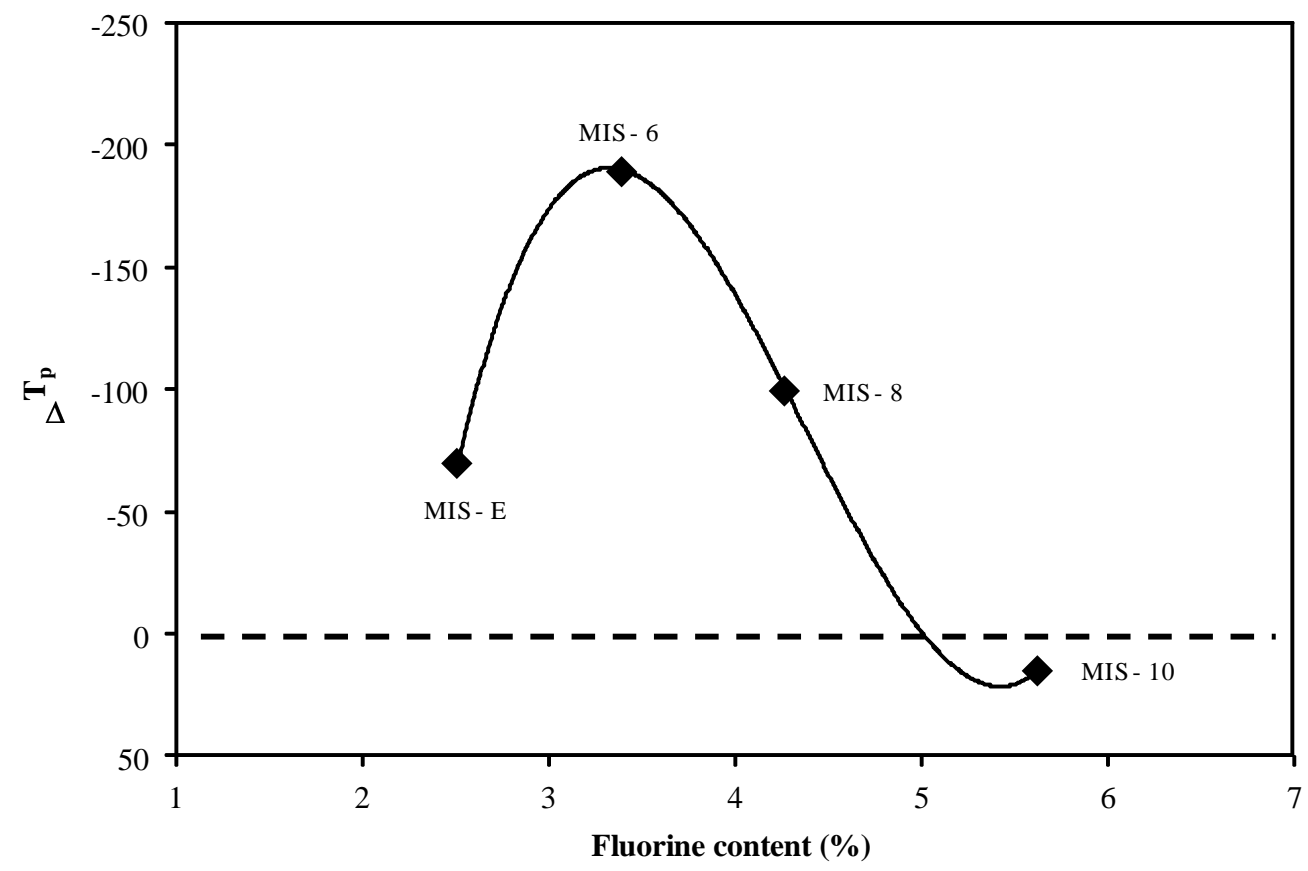

Figure 3. Evolution of $\Delta \mathrm{T}_{\mathrm{p}}$ with fluorine content for each glass composition (The lines are drawn to guide eyes). The errors in $\Delta \mathrm{T}_{\mathrm{p}}$ are approximately $\pm 2-3^{\circ} \mathrm{C}$.

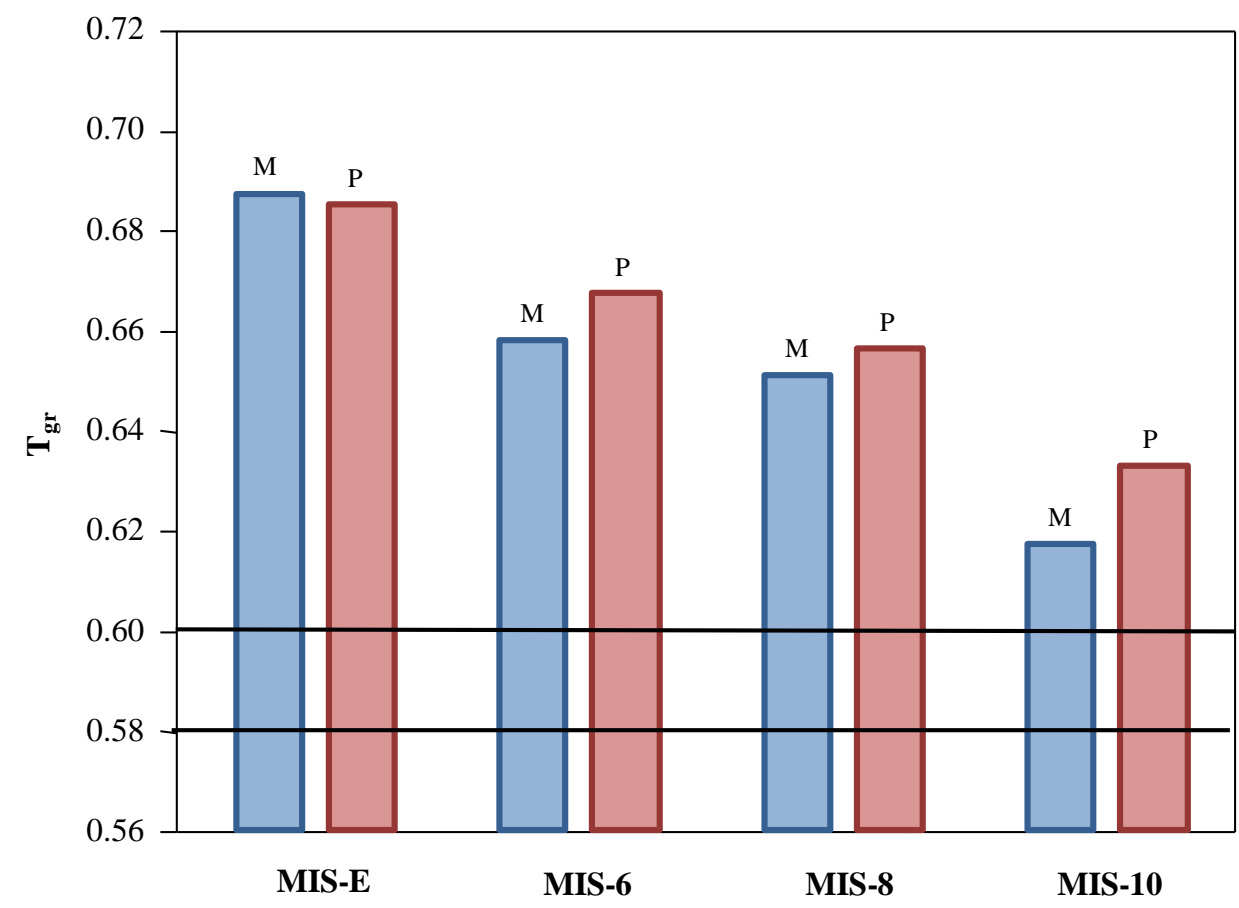

Figure 4. Values of $\mathrm{T}_{\mathrm{gr}}$ for the different glass compositions in both monolithic and powder state. The lines establish the gap between surface $\left(\mathrm{T}_{\mathrm{gr}}>0.58-0.60\right)$ and bulk $\left(\mathrm{T}_{\mathrm{gr}}<0.58-0.60\right)$ crystallisation. The errors in $\mathrm{T}_{\mathrm{gr}}$ are approximately $\pm 2-3^{\circ} \mathrm{C}$. 


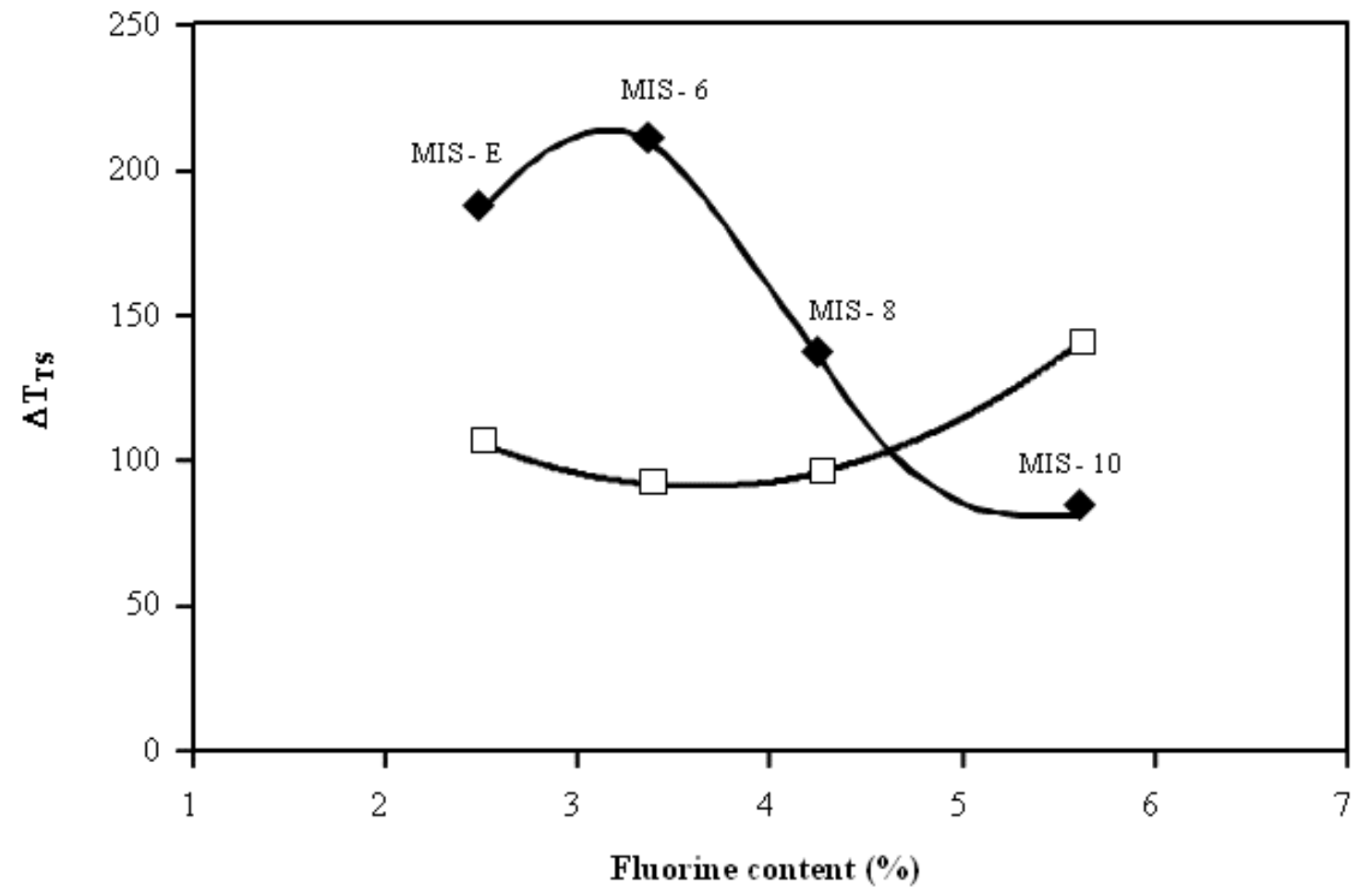

Figure 5. Evolution of $\Delta \mathrm{T}_{\mathrm{TS}}$ with fluorine content for both powder and bulk glass samples. The errors in $\Delta \mathrm{T}_{\mathrm{TS}}$ are approximately $\pm 2-3^{\circ} \mathrm{C}$.

Figure 6 represents the completion of the GS study of the glasses. It illustrates the $\mathrm{K}_{\mathrm{H}}, \mathrm{K}_{\mathrm{W}}$ and $\mathrm{K}_{\mathrm{LL}}$ parameters, which demonstrate the tendency for devitrification during the heating process, i.e., the higher the value of these parameters, the more difficult it is to obtain a crystallised material. It is possible to determine the critical cooling rate $\left(\mathrm{q}_{\mathrm{c}}\right)$ from the $\mathrm{K}_{\mathrm{H}}, \mathrm{K}_{\mathrm{W}}$ and $\mathrm{K}_{\mathrm{LL}}$ parameters, which is indicative of the glass forming ability (GFA) of these glasses, as described previously. Table 3 shows the $\mathrm{q}_{\mathrm{c}}$ values calculated from the different GS parameters.

To confirm the effect of fluorine on the GFA of these glasses, a new assay aimed at evaluating this property "in situ" was conducted by DSC scans that simulate the melting cycle used in the preparation of the glasses. Accordingly, a mixture of raw materials of each glass composition was heated in the DSC equipment to a maximum of $1450^{\circ} \mathrm{C}$ with a heating rate of $50{ }^{\circ} \mathrm{C} / \mathrm{min}$ and held at the melting temperature for $30 \mathrm{~min}$. Subsequently, the sample was cooled to room temperature at $50^{\circ} \mathrm{C} / \mathrm{min}$ (higher cooling rates are unachievable by the equipment) and immediately subjected to a new heating ramp at $50^{\circ} \mathrm{C} / \mathrm{min}$ to $1450^{\circ} \mathrm{C}$. Thus, the GFA of the melts can be evaluated with different compositions from the DSC curves that were recorded during the first cooling step (Figure 7a) and the GS of the glasses from the DSC curves recorded 
R. Casasola, J.M. Pérez, M. Romero. Effect of fluorine content on glass stability and the crystallisation mechanism for glasses in the $\mathrm{SiO}_{2}-\mathrm{CaO}-\mathrm{K}_{2} \mathrm{O}-\mathrm{F}$ system

during the second heating ramp (Figure $7 \mathrm{~b}$ ). To know the nature of the possible crystalline phases developed on cooling (Fig. 7a), the mixture of raw materials of each glass composition were melted in an electric furnace under the same conditions used for "in situ" DSC runs. With the aim of promoting the development of crystalline phases, the melts were cooling at $50^{\circ} \mathrm{C} / \mathrm{min}$ from $1450^{\circ} \mathrm{C}$ to $1070^{\circ} \mathrm{C}$ and then hold for $30 \mathrm{~min}$ at $1070^{\circ} \mathrm{C}$. After that, the samples removed from the oven and cooled in air. Figure 8 shows the XRD patterns of the resulting materials.
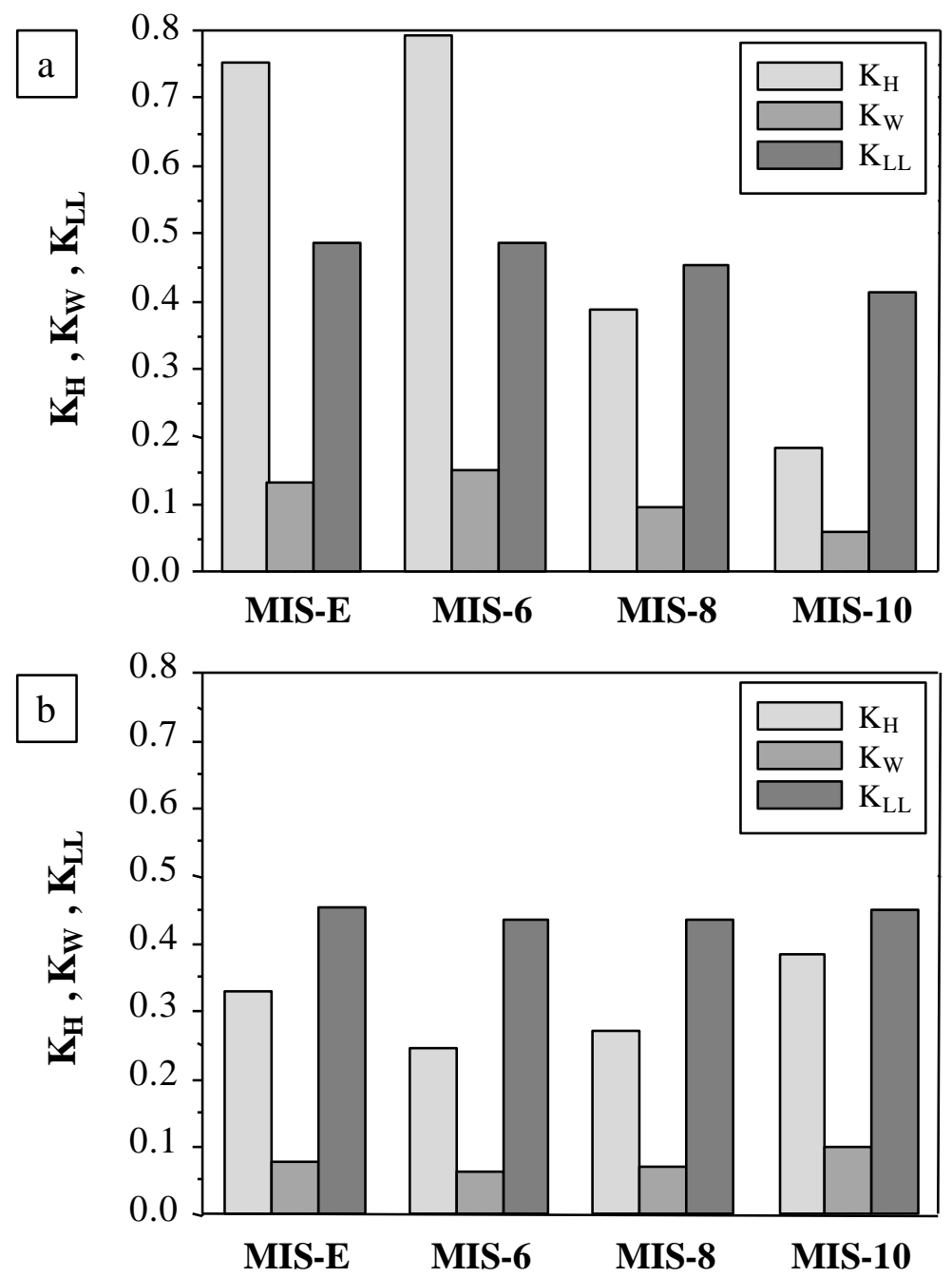

Figure 6. Hrüby, Weinberg and Lu-Liu parameters for a) monolithic and b) powder glass samples. 
R. Casasola, J.M. Pérez, M. Romero. Effect of fluorine content on glass stability and the crystallisation mechanism for glasses in the $\mathrm{SiO}_{2}-\mathrm{CaO}-\mathrm{K}_{2} \mathrm{O}-\mathrm{F}$ system
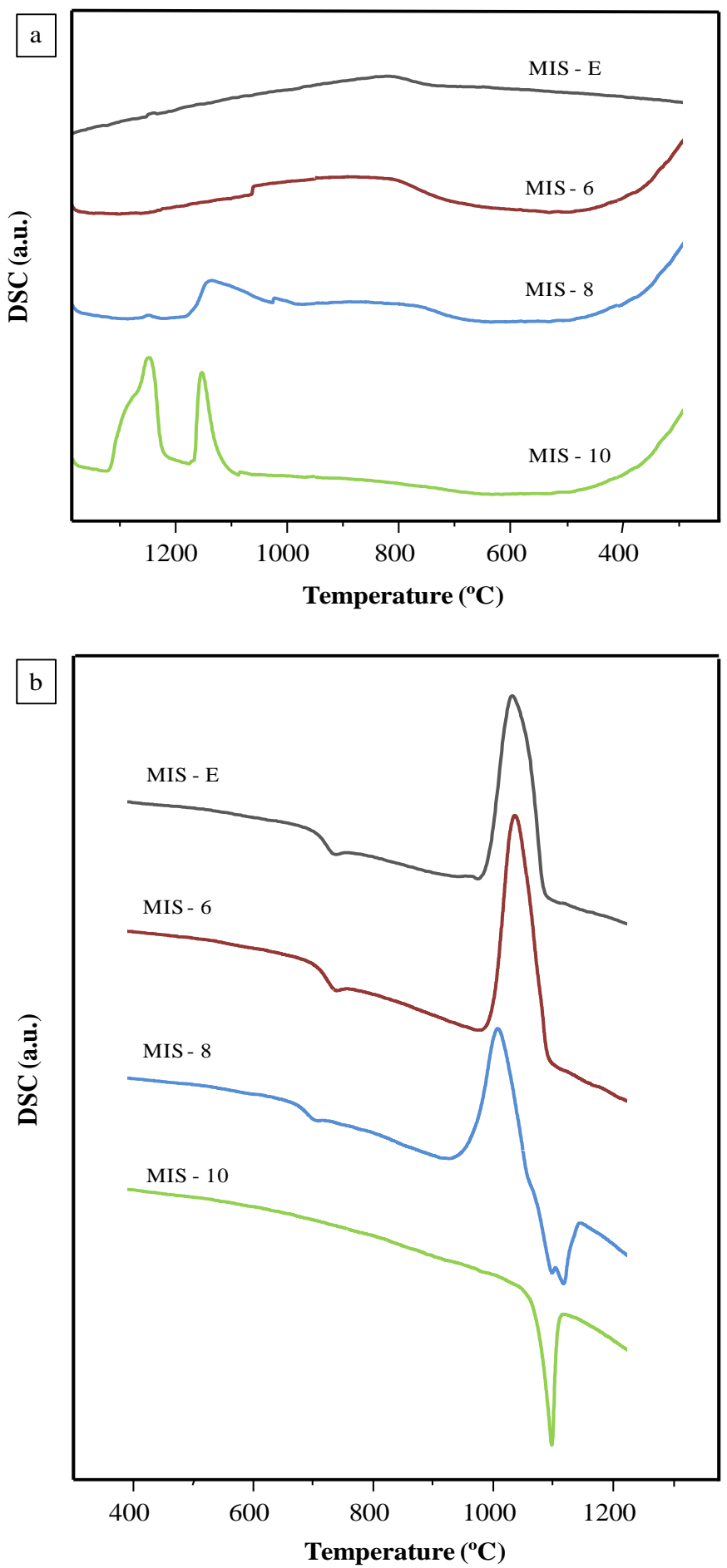

Figure 7. DSC curves from a mixture of raw materials of each glass composition, which were heated in the DSC equipment to $1450^{\circ} \mathrm{C}$ and held for $30 \mathrm{~min}$. Subsequently, the samples were cooled to room temperature at $50^{\circ} \mathrm{C} / \mathrm{min}$ (Fig. 7a) and immediately subjected to a new heating ramp at $50^{\circ} \mathrm{C} / \mathrm{min}$ to $1450^{\circ} \mathrm{C}$ (Fig. $7 \mathrm{~b}$ ). 
R. Casasola, J.M. Pérez, M. Romero. Effect of fluorine content on glass stability and the crystallisation mechanism for glasses in the $\mathrm{SiO}_{2}-\mathrm{CaO}-\mathrm{K}_{2} \mathrm{O}-\mathrm{F}$ system

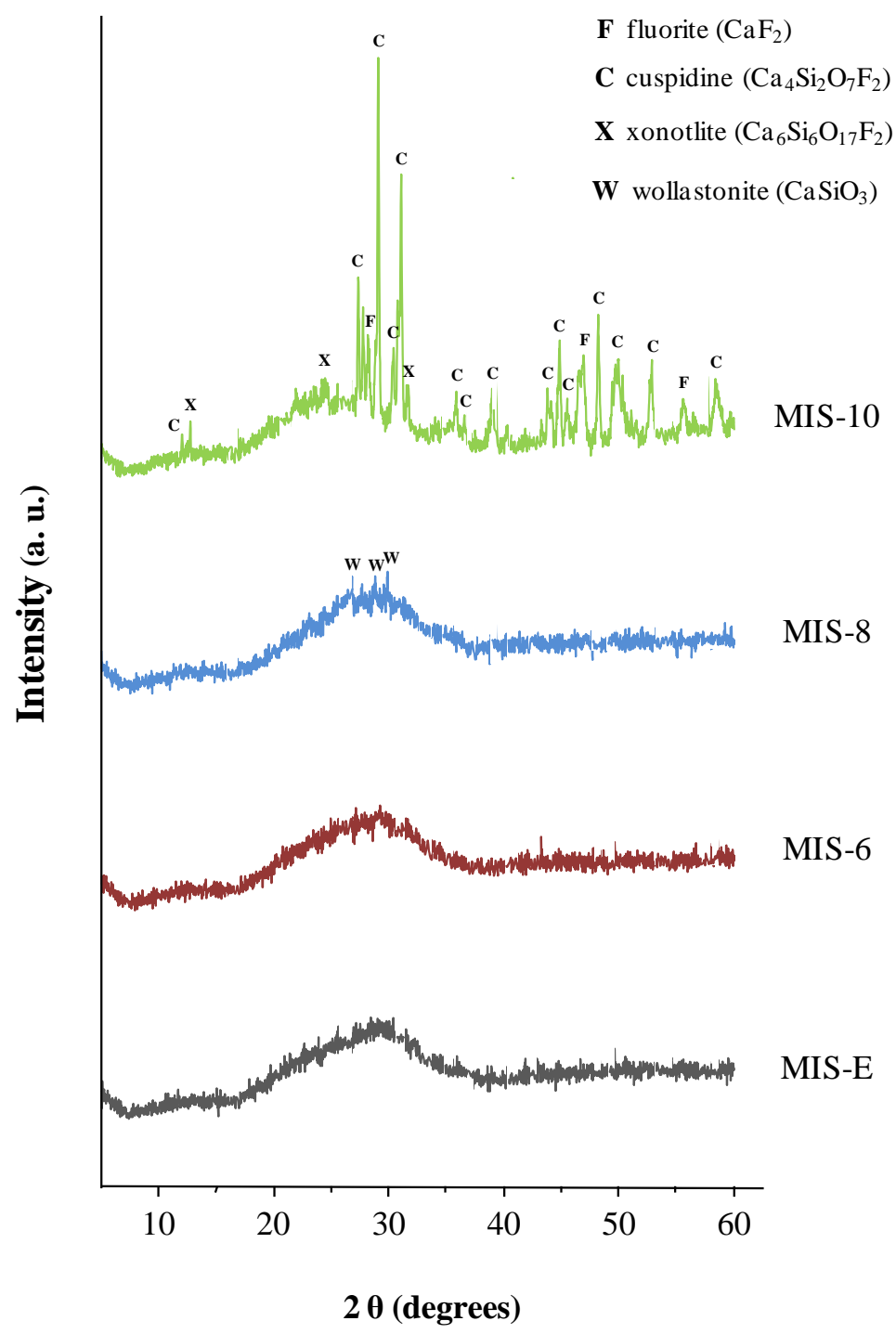

Figure 8. XRD patterns of the materials resulted after stopping the melt cooling at $1070^{\circ} \mathrm{C}$ for $30 \mathrm{~min}$.

Table 3. Critical cooling rates, $\mathrm{q}_{\mathrm{c}}$, calculated from the different GS parameters

$$
\mathrm{q}_{\mathrm{W}}(\mathrm{K} / \min ) \quad \mathrm{q}_{\mathrm{H}}(\mathrm{K} / \min ) \quad \mathrm{q}_{\mathrm{LL}}(\mathrm{K} / \min )
$$

\begin{tabular}{r|rrr}
\hline MIS-E & 21.1 & 0.3 & 6.9 \\
MIS-6 & 2.8 & 0.1 & 1.6 \\
MIS-8 & 26.4 & 22.1 & 19.7 \\
MIS-10 & $5,366.5$ & $8,534.0$ & $4,908.4$ \\
\hline
\end{tabular}


R. Casasola, J.M. Pérez, M. Romero. Effect of fluorine content on glass stability and the crystallisation mechanism for glasses in the $\mathrm{SiO}_{2}-\mathrm{CaO}-\mathrm{K}_{2} \mathrm{O}-\mathrm{F}$ system

Journal of Non-Crystalline Solids 378 (2013) 25-33; DOI: 10.1016/j.jnoncrysol.2013.06.006

To confirm the effect of fluorine on the preferential mechanism (surface or bulk) by which the process of crystallisation occurs, bulk samples of each glass composition were subjected to thermal treatment to promote the onset of crystal growth. With the aim of freezing the microstructure of the glass-ceramic materials at the beginning of the crystallisation process, heat treatments resulted in a low degree of crystallisation were selected for each glass compositions. Figures 9 and 10 show the microstructure observed by FESEM and the crystalline phases developed in the heat-treated samples.
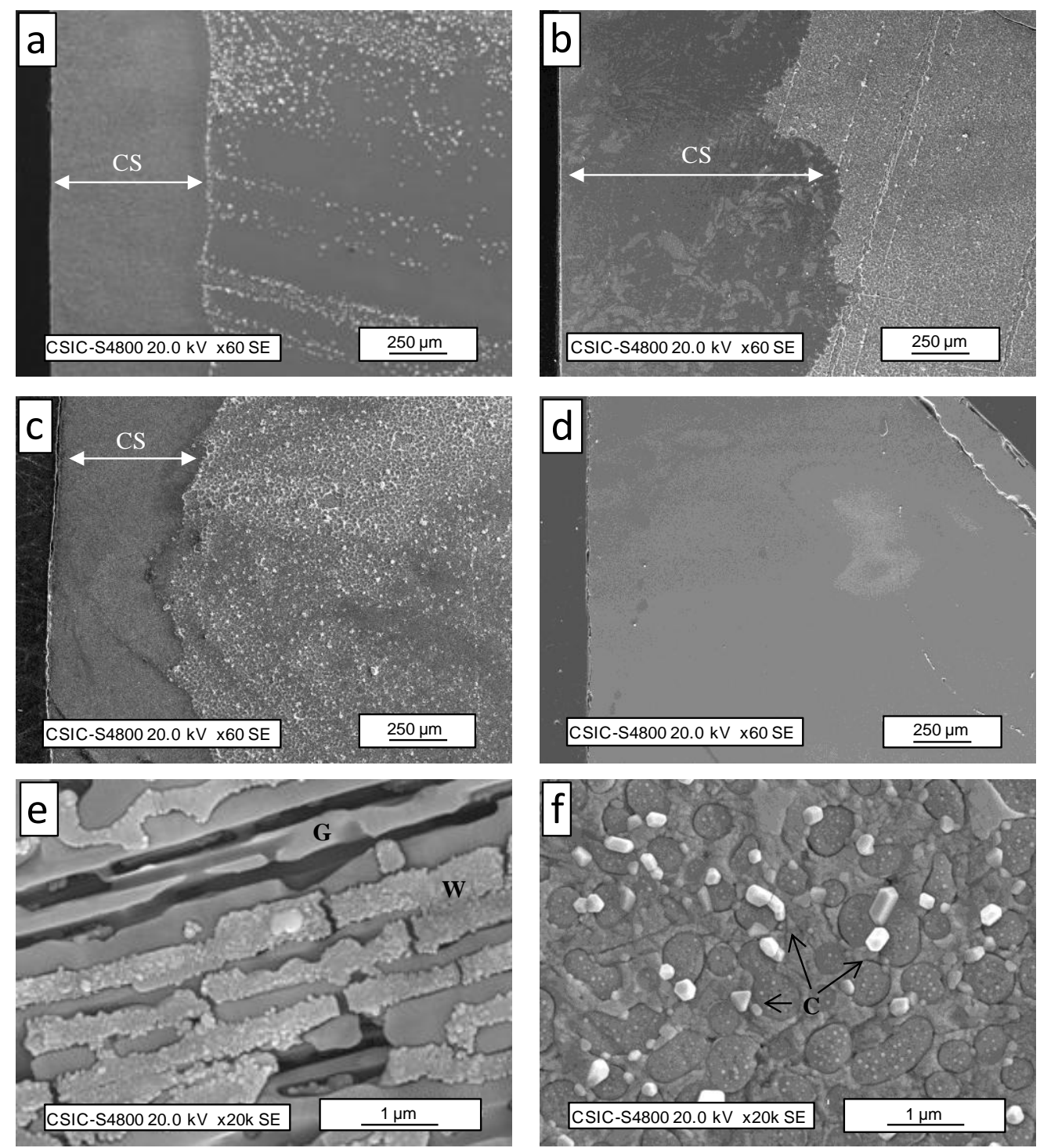

Figure 9. FESEM micrographs of heat-treated samples at the early stages of the crystallisation process. a) MIS-E heated at $1100^{\circ} \mathrm{C}$ for $2 \mathrm{~min}$; b) MIS-6 heated at $900^{\circ} \mathrm{C}$ for $30 \mathrm{~min}$; c) MIS-8 heated at $900^{\circ} \mathrm{C}$ for $30 \mathrm{~min}$; d) MIS-10 heated at $750^{\circ} \mathrm{C}$ for $30 \mathrm{~min}$; e) detail of the crystallisation shell developed in MIS-E, MIS-6 and MIS-8 glasses and f) detail of cuspidine crystals dispersed throughout the entire volume of MIS-10 glass. 


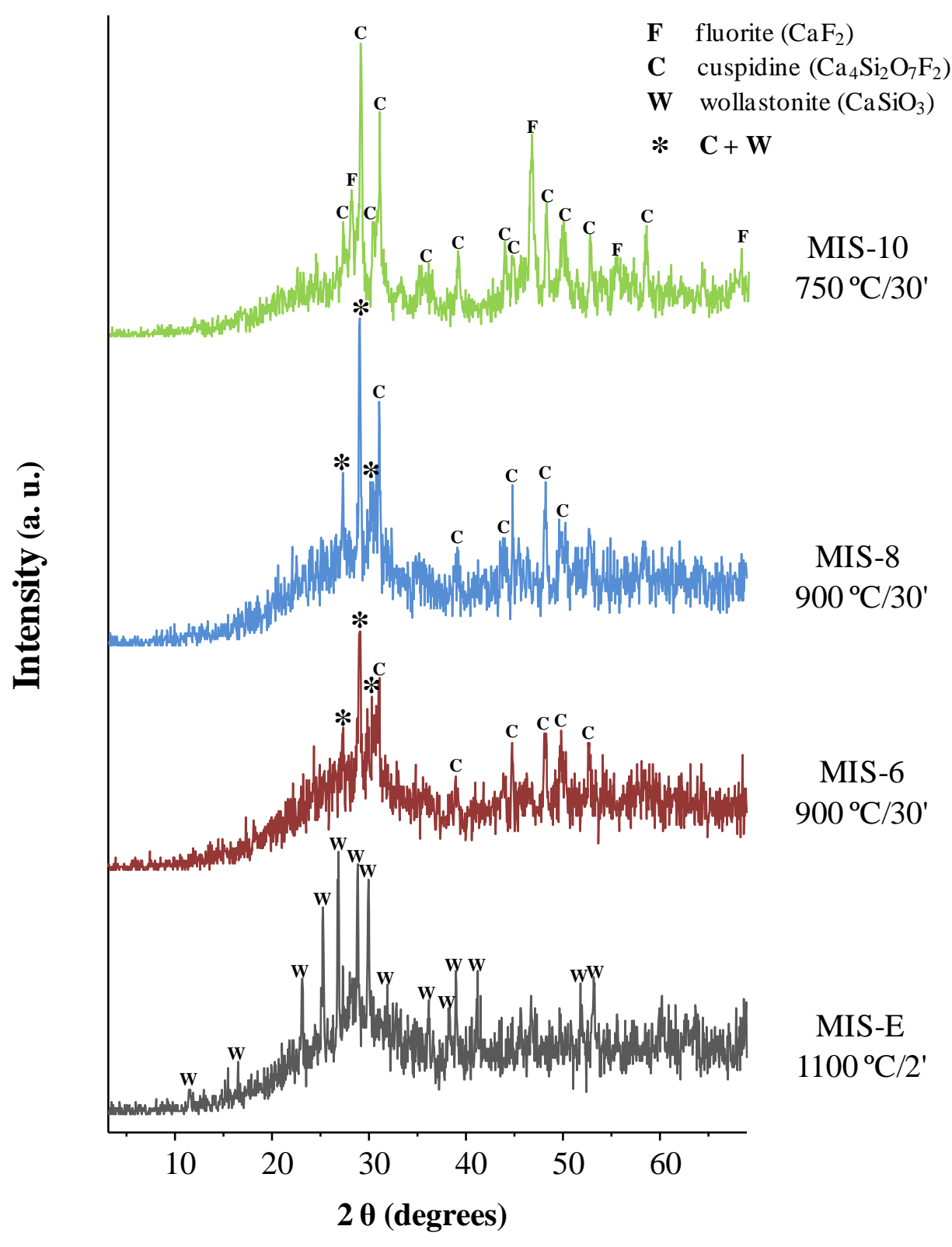

Figure 10. XRD patterns of the glass-ceramics at the early stages of the crystallisation process.

\section{Discussion}

As expected, the chemical analysis shown in Table 1 reveals than the fluorine content increases from MIS-E composition to MIS-10 composition, but fluorine volatilisation occurs during the melting process in all glasses. Thus, the fluorine content remaining in the glass network is approximately 56 wt. $\%$ of the initial fluorine in the batch compositions. In addition to the fluorine reduction, a slight decrease in the $\mathrm{SiO}_{2}$ and $\mathrm{K}_{2} \mathrm{O}$ contents is also observed, which 
R. Casasola, J.M. Pérez, M. Romero. Effect of fluorine content on glass stability and the crystallisation mechanism for glasses in the $\mathrm{SiO}_{2}-\mathrm{CaO}-\mathrm{K}_{2} \mathrm{O}-\mathrm{F}$ system

indicates that fluorine loss is primarily due to its volatilisation as $\mathrm{SiF}_{4}$ and $\mathrm{KF}$ during melting. This finding is highlighted in previous works on fluoride glasses [25]. The occurrence of $\mathrm{Al}_{2} \mathrm{O}_{3}$ in all glass compositions is also observed, as shown in Table $1 . \mathrm{Al}_{2} \mathrm{O}_{3}$ is not introduced in the original batches and is derived from the corrosion of the crucible by the molten glass, which induces chemical reactions that cause the extraction of silica and alumina from the surfaces of the refractories [26].

The XRD diffractograms of the powder glass samples (Fig. 1) indicate that MIS-E, MIS-6 and MIS- 8 glasses are completely amorphous. In contrast, the pattern of the glass MIS-10 sample shows three diffraction peaks, which indicate the development of fluorite $\left(\mathrm{CaF}_{2}, \mathrm{PDF}\right.$ 87-0971) during cooling. However, the amount of the glassy phase in the sample is significant, as indicated by the high intensity of the amorphous halo. This result demonstrates that the melt derived from the MIS-10 composition has a higher tendency to crystallise on cooling.

Table 2 reveals that the presence of fluorine causes significant shifts in characteristic glass temperatures as fluorine content increases: $\mathrm{T}_{\mathrm{g}}$ decreases by approximately $80^{\circ} \mathrm{C}$, and $\mathrm{T}_{\mathrm{x}}$ decreases by approximately $130^{\circ} \mathrm{C}$ and $185^{\circ} \mathrm{C}$ in bulk and power samples, respectively. This tendency is due to $\mathrm{F}^{-}$ions that exert a fluidising action in glasses. Fluorine ions have an ionic radio close to oxygen ions and therefore, $\mathrm{F}^{-}$ions can partially substitute to $\mathrm{O}^{2-}$ in the glass network. Nevertheless, contrary to oxygen, fluorine ions are monovalent and create reticular discontinuity points that lead to a decrease in viscosity [27]. Regardless of glass composition, the value of $\mathrm{T}_{\mathrm{g}}$ corresponds to a viscosity between $10^{13}$ and $10^{13.5} \mathrm{dPa} \cdot \mathrm{s}$. From a structural standpoint, $\mathrm{T}_{\mathrm{g}}$ denotes a stage in which the atoms in the glass network are capable of vibration. Below $\mathrm{T}_{\mathrm{g}}$, the vibration of atoms is mainly local and does not involve the surrounding atoms. Above $\mathrm{T}_{\mathrm{g}}$, the amplitude of the vibration of the atoms increases and the mobility of the atoms improves as more heat energy is applied to the system. Thus, the formation of crystalline phases is feasible. In this case, the shift of $\mathrm{T}_{\mathrm{g}}$ and $\mathrm{T}_{\mathrm{x}}$ to lower temperatures as fluorine content increases indicates that fluorine favours the devitrification process of the glass. This effect of $\mathrm{F}^{-}$ions to exert a fluidising action in glasses is well known in glass science and different authors have reported the decrease of $T_{g}$ and $T_{x}$ with increasing fluorine content in several silicate [28, 29] aluminosilicate [30], silicophosphate [31, 32] oxynitride [33] glasses.

The DSC curve of the MIS-E glass with the lower fluorine content $(2.51 \mathrm{wt} . \%)$ indicates that the glass particle size affects the crystallisation process of this composition. Therefore, the thermogram corresponding to the powdered sample exhibits a well-defined exothermic peak, 
R. Casasola, J.M. Pérez, M. Romero. Effect of fluorine content on glass stability and the crystallisation mechanism for glasses in the $\mathrm{SiO}_{2}-\mathrm{CaO}-\mathrm{K}_{2} \mathrm{O}-\mathrm{F}$ system

which displays a shoulder at the beginning of the crystallisation effect. In the DSC curve that was recorded for the bulk sample, the crystallisation process is shifted to higher temperatures, which results in a single and wider band of lower intensity. This behaviour indicates that the devitrification of MIS-E glass occurs through surface and volume crystallisation mechanisms, of which the surface crystallisation is predominant.

Conversely, the composition MIS-10 with the higher fluorine content (5.63 wt.\%) exhibits a crystallisation behaviour that is contrary to the crystallisation behaviour observed for the MIS-E glass. In this case, the bulk crystallisation is the essential mechanism. This result is likely because MIS-10 glass is not completely amorphous. As previously noted in Fig.1, its XRD pattern indicates the segregation of $\mathrm{CaF}_{2}$ crystals, which will most likely act as nucleating sites in a subsequent thermal treatment.

The glass compositions MIS-6 and MIS-8 (3.39 and 4.27 wt.\% of fluorine, respectively) depict an intermediate crystallisation behaviour between MIS-E and MIS-10 glasses. Similar to MIS$\mathrm{E}$, the crystallisation process shifts to higher temperatures in the DSC curves, which correspond to bulk samples. However, the intensity of the crystallisation peaks in this case does not vary significantly with glass particle size, which indicates the absence of a crystallisation mechanism that clearly predominates in the crystallisation process of the MIS- 6 and MIS- 8 glasses.

Considering the DSC curves recorded for the powder glass samples, there are two effects associated with the fluorine content in the glass composition. The temperature at the maximum of the crystallisation peak $\left(T_{\mathrm{p}}\right)$ shifts to lower temperatures, from $915^{\circ} \mathrm{C}$ (MIS-E) to $775^{\circ} \mathrm{C}$ (MIS-10), when the fluorine content increases, which denotes that fluorine ions enhance the ability of the glass to devitrify by a surface crystallisation mechanism. However, the intensity of the exothermic peak decreases simultaneously, which demonstrates the development of a lower number of crystals.

Regarding monolithic glass samples, Fig. 2 shows that the predominance of bulk crystallisation is highly affected by the fluorine percentage in the composition of glasses. Hence, $T_{p}$ is shifted by $50^{\circ} \mathrm{C}$ from MIS-E to MIS-6, in which $3.39 \%$ of fluoride ions are contained in the sample. This shift towards a higher temperature indicates that fluorine inhibits the devitrification of glass through a volume crystallisation mechanism at such concentrations. However, this tendency changes when a higher percentage of fluorine is present in the glass. Thus, $T_{p}$ decreases by approximately $85^{\circ} \mathrm{C}$ from MIS-6 to MIS- 8 and decreases by approximately $175^{\circ} \mathrm{C}$ 
R. Casasola, J.M. Pérez, M. Romero. Effect of fluorine content on glass stability and the crystallisation mechanism for glasses in the $\mathrm{SiO}_{2}-\mathrm{CaO}-\mathrm{K}_{2} \mathrm{O}-\mathrm{F}$ system

from MIS-8 to MIS-10. Furthermore, the DSC curve of the latter confirms a significant increase in the intensity of the crystallisation peak, which indicates the development of a greater number of crystals of lower size and leads to homogenous microstructures. Because they act as heterogeneous nucleation sites and promote crystallisation, the segregation of $\mathrm{CaF}_{2}$ crystals during the cooling of the melt enhances the devitrification of the glass in a subsequent thermal treatment through a bulk crystallisation mechanism.

As mentioned previously, an increase in fluorine content produces two effects: it not only increases the ability of the glass to devitrify by a surface crystallisation mechanism but also increases the devitrification of the glass by a bulk crystallisation mechanism, from the $\mathrm{CaF}_{2}$ crystals existing in the parent glass. Because of these two conflicting tendencies, a minimum $\Delta \mathrm{T}_{\mathrm{p}}$ value that corresponds to MIS-6 glass composition is depicted in Fig. 3. MIS-E, MIS-6 and MIS-8 with lower fluorine contents exhibit negative values of $\Delta T_{p}$, which indicate that the mechanism of surface crystallisation is predominant in these glasses. In contrast, MIS-10 is the only glass that exhibits a positive value of $\Delta \mathrm{T}_{\mathrm{p}}$, which corroborates the prevalence of bulk crystallisation in this composition.

Figure 4 shows that for a given glass composition, the particle size of the sample leads to an unappreciated variation in $\mathrm{T}_{\mathrm{gr}}$, because both powder and monolithic samples are prepared from the same melt. In contrast, the fluorine content in the glass composition has a considerable effect on the value of $\mathrm{T}_{\mathrm{gr}}$. An increase in the percentage of fluorine in the glass composition results in a significant decrease in $\mathrm{T}_{\mathrm{gr}}$, which indicates that the MIS-10 composition generates a melt with a higher tendency to crystallise during cooling. This result agrees with those shown in Fig. 1, which illustrate the precipitation of fluorite crystals during the cooling of MIS-10. According to James [21] and Zanotto [22, 23], an increase in fluorine content leads to a change in the crystallisation process of these glasses, from a mechanism of surface crystallisation that is predominant in the glasses with lower fluoride content to a prevailing volume crystallisation in MIS-10 glass. For this composition, the value $\mathrm{T}_{\mathrm{gr}}$ is slightly higher than $0.58-0.60$ due to the occurrence of minor surface crystallisation, as can be deduced from Fig. 2d.

Considering $\Delta \mathrm{T}_{\mathrm{TS}}$, Fig. 5 confirms the trend deduced from Figs. 3 and 4 relating to the predominance of a surface or bulk crystallisation mechanism in these glasses. Thus, in MIS-E, MIS-6 and MIS-8 glasses, the lower values of $\Delta \mathrm{T}_{\mathrm{TS}}$, which correspond to the powder samples, indicate that surface crystallisation is the predominant mechanism in the devitrification process 
R. Casasola, J.M. Pérez, M. Romero. Effect of fluorine content on glass stability and the crystallisation mechanism for glasses in the $\mathrm{SiO}_{2}-\mathrm{CaO}-\mathrm{K}_{2} \mathrm{O}-\mathrm{F}$ system

of these glasses. Nevertheless, this tendency is inverted in MIS-10 glass, which is the only glass that exhibits a $\Delta \mathrm{T}_{\mathrm{TS}}$ value higher for the monolithic sample, and corroborates the prevalence of bulk crystallisation in this composition. Fig. 5 highlights two aspects: the $\Delta \mathrm{T}_{\mathrm{TS}}$ range is relatively narrower in powder samples $\left(90-141^{\circ} \mathrm{C}\right)$ than in the monolithic samples $\left(83-186^{\circ} \mathrm{C}\right)$ and the curve corresponding to the monolithic samples depicts the same trace as the $\Delta T_{p}$ curve in Fig. 3. Both aspects denote that the fluorine content of these glasses exerts a greater influence on volume crystallisation and hence, the prevalence of this mechanism determines the predominant mechanism in the overall crystallisation process.

Figure 6 shows that although the $\mathrm{K}_{\mathrm{H}}, \mathrm{K}_{\mathrm{W}}$ and $\mathrm{K}_{\mathrm{LL}}$ parameters vary qualitatively in the same manner, the magnitude of this variation is different from one parameter to another. Thus, $\mathrm{K}_{\mathrm{H}}$ is the most sensitive to the variation of fluoride in the glass composition. Considering $\mathrm{K}_{\mathrm{H}}$, Fig. 6 illustrates that surface crystallisation is prevalent in MIS-E, MIS-6 and MIS-8 glasses, whereas bulk crystallisation predominates in MIS-10 glass.

Table 3 shows the $\mathrm{q}_{\mathrm{c}}$ values calculated from the GS parameters. The fluorine content also has a considerable influence on the GFA of these glasses. In MIS-6 glass, whose composition results from adding a small percentage of fluorine to MIS-E glass, the F- ions cause an increase in GFA and, consequently, they cause a decrease in the critical cooling rate. However, an increased presence of fluorine in the glass composition leads to a greater difficulty of vitrifying the melt on cooling, as evidenced by the enlarged value of $\mathrm{q}_{\mathrm{c}}$; in the case of MIS-10, it increases by several orders of magnitude. The high value of $\mathrm{q}_{\mathrm{c}}$ exhibited by MIS-10 glass denotes the unlikelihood of preventing crystallisation on cooling and justifies the presence of fluorite in the base glass (Fig. 1).

Figures 7 and 8 confirm the effect of fluorine on the GFA of these glasses. It is patent from Fig. 7a that MIS-E and MIS-6 melts do not undergo any crystallisation processes during cooling. The only effect observed in their DSC curves is a jump in the baseline at $781^{\circ} \mathrm{C}$ (MIS-E) and $767^{\circ} \mathrm{C}$ (MIS-6), which corresponds to their respective $\mathrm{T}_{\mathrm{g}}$. The XRD patterns of the materials resulted after stopping the cooling at $1070^{\circ} \mathrm{C}$ for $30 \mathrm{~min}$ (Fig. 8), show that indeed, any crystalline phase develops from MIS-E and MIS-6 melts. This result reveals high GFA of MISE and MIS-6 compositions and is in agreement with the low critical cooling rates shown in Table 3. In contrast, an exothermic band centred at $1135^{\circ} \mathrm{C}$ is evident in the DSC curve corresponding to the MIS-8 liquid, which demonstrates the existence of a crystallisation process during the cooling of this melt composition. However, the existence of $\mathrm{T}_{\mathrm{g}}$, which was clearly 
R. Casasola, J.M. Pérez, M. Romero. Effect of fluorine content on glass stability and the crystallisation mechanism for glasses in the $\mathrm{SiO}_{2}-\mathrm{CaO}-\mathrm{K}_{2} \mathrm{O}-\mathrm{F}$ system

observed by the jump at $732^{\circ} \mathrm{C}$, indicates that minor crystallisation occurred and most of the MIS-8 liquid vitrified. Fig. 8 supports this results and the pattern of the material resulted after halting the cooling of MIS-8 melt shows a clear amorphous halo with low intensity peaks corresponding to the development of wollastonite $\left(\mathrm{CaSiO}_{3}, \mathrm{PDF} 43-1460\right)$ in low extend. Thus, the GFA of MIS-8 is slightly lower than MIS-E and MIS-6 and, hence, its critical cooling rate for preventing crystallisation during the cooling of the liquid is somewhat higher, as shown in Table 3. Finally, significant crystallisation occurs on cooling of the MIS-10 liquid, which is evidenced by two well-defined exothermic peaks at 1245 and $1150^{\circ} \mathrm{C}$, and by the lack of $\mathrm{T}_{\mathrm{g}}$ in the DSC curve. Both effects denote the extreme difficulty of MIS-10 composition to vitrify; therefore, avoiding crystallisation would only be possible by cooling at an extremely high rate, as highlighted in Table 3. The XRD pattern in Fig. 8 indicates that the devitrification of MIS-10 on cooling leads to a glass-ceramic with a high crystallisation degree and that the exothermic effects observed in Fig. 7 are associated to the growth of cuspidine $\left(\mathrm{Ca}_{4} \mathrm{Si}_{2} \mathrm{O}_{7} \mathrm{~F}_{2}, \mathrm{PDF}\right.$ 41-1474) and xonotlite $\left(\mathrm{Ca}_{6} \mathrm{Si}_{6} \mathrm{O}_{17} \mathrm{~F}_{2}\right.$, PDF 23-0125) crystals.

The former results on the effect of fluorine on the GFA of these glasses are confirmed from an analysis of the DSC curves recorded during the second heating (Fig. 7b), which show the thermal stability of the cooled samples. MIS-E and MIS-6 compositions depict the typical DSC curve of a glass by showing a well-defined $\mathrm{T}_{\mathrm{g}}$ (at $735^{\circ} \mathrm{C}$ and $728^{\circ} \mathrm{C}$ for MIS-E and MIS-6, respectively) and an exothermic crystallisation effect centred at $1040^{\circ} \mathrm{C}$. The curve corresponding to MIS-8 also shows $\mathrm{T}_{\mathrm{g}}$ at $690^{\circ} \mathrm{C}$ and an exothermic effect at $1010^{\circ} \mathrm{C}$, which indicate that its nature is mainly amorphous. However, both the jump in the baseline and the intensity of the exothermic peak are of lower intensity than those for glasses with minor fluorine content. This finding is due to its minor proportion of remaining glassy phase because the crystalline phase devitrified during cooling. Finally, the DSC curve corresponding to MIS-10 composition exhibits neither $T_{g}$ nor a crystallisation process because this sample was previously crystallised.

Briefly, this study demonstrates that fluorine ions dramatically decrease the GFA of the studied glasses from the $\mathrm{SiO}_{2}-\mathrm{CaO}-\mathrm{K}_{2} \mathrm{O}-\mathrm{F}$ system. As Fokin et al. [25] highlighted, this tendency can be explained by an enhanced movement or molecular rearrangement of the basic units of the melt with decreasing viscosity, because an increase in fluorine ions concentration in the glass composition results in liquids that are more fluid. 
R. Casasola, J.M. Pérez, M. Romero. Effect of fluorine content on glass stability and the crystallisation mechanism for glasses in the $\mathrm{SiO}_{2}-\mathrm{CaO}-\mathrm{K}_{2} \mathrm{O}-\mathrm{F}$ system

Figure 9 shows the microstructure developed during the early stages of the devitrification process in the glasses investigated in this study. Crystallisation of MIS-E, MIS- 6 and MIS-8 occurs through a surface mechanism. The crystal growth begins at the glass surface (Fig.9a-c), which results in the formation of a crystalline shell (CS) that entirely covers the glass sample, whereas crystallisation is not observed in the interior. In contrast, no crystallisation crust is observed in the thermal treated MIS-10 glass (Fig.9d), which indicates that, in this case, crystallisation proceeds through a volume crystallisation process rather than through a surface mechanism process. High magnification observations allow examination of the microstructure in more detail. The crystallisation shells of MIS-E, MIS-6 and MIS-8 (Fig.9e) glasses are composed of wollastonite crystals (W) integrated in an amorphous or glassy phase (G). The main difference between the phases are the relative proportions of $\mathrm{SiO}_{2}$ and $\mathrm{F}_{2}$ in their composition; the average value of the $\mathrm{SiO}_{2} / \mathrm{F}_{2}$ ratio varies from 2.5 (glassy phase) to 7.8 (crystals). Concerning the thermal treated MIS-10 glass (Fig.9f), bulk crystallisation occurs through the precipitation of small polyhedral crystals of cuspidine dispersed throughout the entire volume of the sample.

Figure 10 shows the X-ray diffractograms of glass-ceramics showed in Fig. 9. It is evident that all these materials are found in an early stage of crystallisation, as denoted by the significant amorphous halo indicating a major amount of residual glassy phase and consequently a low crystallisation degree. The patterns show that the devitrification starts with the growth of wollastonite in MIS-E glass with lower fluorine content; wollastonite and cuspidine in MIS-6 and MIS- 8 glasses; whereas cuspidine is the crystalline phase developed at the beginning of crystallisation in MIS-10 glass. It is also clear from Fig. 10 that miserite is absent in the initial step of crystallisation of any of the glasses studied. This result can be unexpected since the studied glasses are formulated based on the stoechiometric composition of miserite. However, Pinckney et al. [3] obtained similar results in their study on crystallisation in miserite-based glasses. They pointed out that miserite development is favoured when a sinter-crystallisation process from small size glass particles is used to produce the glass-ceramics. In contrast, the internal crystallisation of bulk glass samples favours xonotlite over miserite. Accordingly, the absence of miserite in Fig. 10 may be justified by the fact that crystallisation is conducted on bulk samples.

On the other hand, a higher level of fluorine is required to stabilize cuspidine $\left(4 \mathrm{CaO} \cdot 2 \mathrm{SiO}_{2} \cdot \mathrm{F}_{2}\right)$ relative to miserite $\left(\mathrm{K}_{2} \mathrm{O} \cdot 10 \mathrm{CaO} \cdot 16 \mathrm{SiO}_{2} \cdot \mathrm{F}_{2}\right)$, which would suggest that miserite crystallisation would be favoured in these low fluorine glasses. Cuspidine over miserite development could be 
R. Casasola, J.M. Pérez, M. Romero. Effect of fluorine content on glass stability and the crystallisation mechanism for glasses in the $\mathrm{SiO}_{2}-\mathrm{CaO}-\mathrm{K}_{2} \mathrm{O}-\mathrm{F}$ system

justified by a noticeable difference between the activation energies associated to the crystallisation of both crystalline phases, so that cuspidine crystallisation was kinetically favoured. Carli and Righi [34] provided estimation of activation energy for cuspidine crystallisation in mould flux glasses, resulting $\mathrm{E}_{\mathrm{a}}=315 \mathrm{~kJ} / \mathrm{mol}$. Unfortunately, to our knowledge the literature shows a lack of kinetic data on miserite crystallisation in glasses.

Finally, Pinckney et al. [3] also concluded that miserite phase is stabilized over other morecommon phases, such as xonotlite or wollastonite, by the incorporation of certain higher valence cations $\left(\mathrm{Ce}^{3+}, \mathrm{Y}^{3+}, \mathrm{Ti}^{3+}, \mathrm{P}^{5+}, \mathrm{Nb}^{5+} \ldots\right)$ to the glass composition. Such cations are absent in the composition of the glasses formulated in our study and hence, wollastonite or cuspidine over miserite are promoted.

\section{Conclusions}

Four glass compositions in the $\mathrm{SiO}_{2}-\mathrm{CaO}-\mathrm{K}_{2} \mathrm{O}-\mathrm{F}$ system were evaluated by DSC to determine the effect of fluorine content on their glass stability, preferential crystallisation mechanism and glass forming ability. The results conclude that an increase in the percentage of fluorine in the glass composition lowers the glass transition temperature and favours the beginning of a crystallisation process. Fluorine content leads to a change in the process of crystallisation of these glasses, from a mechanism of surface crystallisation, which is predominant in the glasses with lower fluoride content (MIS-E, MIS-6 and MIS-8 with 2.51, 3.39 and 4.27 wt.\% of fluorine, respectively), to a prevailing volume crystallisation in MIS-10 (5.63 wt.\% of fluorine) glass. Fluorine content exerts a greater influence on volume crystallisation and, hence, the prevalence of this mechanism determines the predominant mechanism in the overall crystallisation process. MIS-10 glass composition leads to a melt with high tendency to crystallise during cooling, as demonstrated by the Weinberg $\left(\mathrm{K}_{\mathrm{W}}\right)$, Hrubÿ $\left(\mathrm{K}_{\mathrm{H}}\right)$ and Lu-Liu $\left(\mathrm{K}_{\mathrm{LL}}\right)$ parameters. Consequently, the resulting glass exhibits a segregation of $\mathrm{CaF}_{2}$ crystals, which will likely act as nucleating sites in a subsequent thermal treatment.

\section{Acknowledgements}

The authors would like to acknowledge Mrs. P. Díaz for her technical support in the experimental study. R. Casasola and J.M. Pérez express their gratitude to the Spanish National 
R. Casasola, J.M. Pérez, M. Romero. Effect of fluorine content on glass stability and the crystallisation mechanism for glasses in the $\mathrm{SiO}_{2}-\mathrm{CaO}-\mathrm{K}_{2} \mathrm{O}-\mathrm{F}$ system

Journal of Non-Crystalline Solids 378 (2013) 25-33; DOI: 10.1016/j.jnoncrysol.2013.06.006

Research Council (CSIC) for their contract through the JAE Program (JAEPre-08-00456 and JAEDoc-08-00362, respectively), which is co-financed by the European Social Fund. The financial support through the project MAT 2006-05977 is also recognised.

\section{References}

[1] W. Hölland, G. Beall, Glass-Ceramic Technology, second ed., The American Ceramic Society, Ohio, 2002.

[2] R.G. Hill, R.V. Law, M.D. O'Donnell, J. Hawes, N.L. Bubb, D.J. Wood, C.A. Miller, M. Mirsaneh, I. Reaney, J. Eur. Ceram. Soc. 29 (2009) 2185-2191.

[3] L.R. Pinckney, G.H. Beall, R.L. Andrus, J. Am. Ceram. Soc. 82 (1999) 2523-2528.

[4] A. Cruz, F. Chávez, A. Romero, E. Palacios, V. Arredondo, J. Mater. Process. Tech. 182 (2007) 358-362

[5] R. G. Hill, N. Da Costa, R. V. Law, J. Non-Cryst. Solids 351 (2005) 69-74)

[6] L. Zhou, W. Wang, D. Huang, J. Wei, J. Li, Metall. Mater. Trans. B, 43B (2012) 925-936.

[7] J.Ma. Rincón, Polym. Plast. Technol. Eng. 31 (1992) 309-357.

[8] R.L. Thakur, S. Thiagarajan, Cent. Glass Ceram. Res. Inst. Bull. 13 (1966) 33-45.

[9] I.W. Donald, B.L. Metclafe, L.A. Gerrard, S.K. Fong, J. Non-Cryst. Solid. 354 (2008) 301310.

[10] D. Turnbull, Contemporary physics 10 (1969) 473-488.

[11] M.C. Weinberg, Phys. Chem. Glasses 35 (1994) 119-123.

[12] A. Hrubÿ, Czech. Phys. B. 22 (1972) 1187-1193.

[13] Z.P. Lu, C.T. Liu, Acta Mater. 50 (2002) 3501-3512.

[14] Z.P. Lu, C.T. Liu, Phys. Rev. Lett. 91 (2003) 115505-115508.

[15] A.F. Kozmidis-Petrović, Themochim. Acta 499 (2010) 54-60.

[16] M.L.F. Nascimento, L.A. Souza, E.B. Ferreira, E. Zanotto, J. Non-Cryst. Solid. 351 (2005) 3296-308.

[17] M.L.F. Nascimento, N.O. Dantas, Mat. Lett. 61 (2007) 912-916.

[18] I.S. Gutzow, J.W.P. Schmelzer, Glasses and the glass transition, first ed. Springer-Verlag, Weinheim, 2011.

[19] S. Banijamali, B.E. Yekta, H.R. Rezaie, V.K. Marghussian, Thermochim. Acta 488 (2009) 60-65.

[20] H.A. Davies, Phys. Chem. Glasses 17 (1976) 159-173.

[21] P.F. James, In: in: M.H. Lewis (Ed.), Glasses and Glass-Ceramics, Chapman and 
R. Casasola, J.M. Pérez, M. Romero. Effect of fluorine content on glass stability and the crystallisation mechanism for glasses in the $\mathrm{SiO}_{2}-\mathrm{CaO}-\mathrm{K}_{2} \mathrm{O}-\mathrm{F}$ system

Hall, London, 1989, pp. 59-105.

[22] E.D. Zanotto, J. Non-Cryst. Solids 89 (1987) 361-370.

[23] E.D. Zanotto, M.C. Weinberg, Phys. Chem. Glasses 30 (1989) 186-192.

[24] I.W. Donald, B.L. Metclafe, L.A. Gerrard, S.K. Fong, J. Non-Cryst. Solid. 352 (2006) 2993-3001.

[25] S. Likitvanichkul, W.C. Lacourse, J. Mat. Sci. 30 (1995) 6151-6155.

[26] M. Velez, J. Smith, R.E. Moore, Cerâmica 43 (1997) 180-184.

[27] J.M.F. Navarro, El vidrio, 3rd ed. Consejo Superior de Investigaciones Científicas, Madrid, 2003.

[28] A.A. Omar, E.M.A. Hamzawy, M.M. Farag, Ceram. Int. 35 (2009) 301-307.

[29] M. Mirsaneh, I.M. Reaney, P.F. James, J. Am. Ceram. Soc. 89 (2006) 587-595.

[30] A. Stamboulis , R.G. Hill, R.V. Law, J. Non-Cryst. Solids 333 (2004) 101-107.

[31] K.P. O'Flynn, K.T. Stanton, Cryst. Growth Design 10 (2010) 1111-1117.

[32] D.S. Brauer, R.G. Hill, M.D. O’Donnell, Phys. Chem. Glasses: Eur. J. Glass Sci. Technol. B 53 (2012) 27-30.

[33] A.R. Hanifi, A. Genson, W. Redington, M. J. Pomeroy, J. Eur. Ceram. Soc. 32 (2012) 849857

[34] R. Carli, C. Righi, VII International Conference on Molten Slags Fluxes and Salts, The South African Institute of Mining and Metallurgy, 2004. 